\title{
Formation of Oxide Phases in the System Pr-Fe-O
}

\author{
Mira Ristić, ${ }^{\mathrm{a}, *}$ Stanko Popović, ${ }^{\mathrm{b}}$ and Svetozar Musića \\ ${ }^{a}$ Ruđer Bošković Institute, Bijenička cesta 54, P. O. Box 180, Zagreb, HR-10002, Croatia \\ ${ }^{\mathrm{b}}$ Department of Physics, Faculty of Science, University of Zagreb, Zagreb, HR-10000, Croatia
}

RECEIVED MARCH 8, 2013; REVISED JULY 22, 2013; ACCEPTED SEPTEMBER 2, 2013

\begin{abstract}
The formation of oxide phases at $900{ }^{\circ} \mathrm{C}$ in the system $\mathrm{Fe}_{2} \mathrm{O}_{3}-$ " $\mathrm{Pr}_{2} \mathrm{O}_{3}$ " was investigated. With a decrease in the molar fraction of $\mathrm{Fe}_{2} \mathrm{O}_{3}$ a corresponding increase in $\mathrm{PrFeO}_{3}$ was observed. For equal molar fractions of $\mathrm{Fe}_{2} \mathrm{O}_{3}$ and " $\mathrm{Pr}_{2} \mathrm{O}_{3}$ " the formation of $\mathrm{PrFeO}_{3}$ and very small fractions of $\alpha-\mathrm{Fe}_{2} \mathrm{O}_{3}$ plus an additional oxide phase, which could not be identified with certainty, were observed. With further increase in " $\mathrm{Pr}_{2} \mathrm{O}_{3}$ " fraction the praseodymium oxides $\operatorname{Pr}_{6} \mathrm{O}_{11}$ and $\mathrm{PrO}_{2}$ started to become dominant in the phase composition. The small fraction $(<0.02)$ of the same unidentified oxide phase was also obtained when $\mathrm{Pr}(\mathrm{OH})_{3}$ was calcined in air at $900{ }^{\circ} \mathrm{C}$; this was probably a mixture of other praseodymium oxides with different average oxidation numbers of Pr. The results of XRD, ${ }^{57} \mathrm{Fe}$ Mössbauer and FT-IR spectroscopies are discussed. (doi: 10.5562/cca2247)
\end{abstract}

Keywords: $\alpha-\mathrm{Fe}_{2} \mathrm{O}_{3}, \mathrm{PrFeO}_{3}$, praseodymium oxides

\section{INTRODUCTION}

RE-orthoferrites $(\mathrm{RE}=$ rare earth $)$ and their substituted compounds are in the focus of many studies due to their specific magnetic, electrical and chemical properties. These materials have potential applications in solid-state fuel cells, catalysis or as various types of sensors. The microstructural properties of RE-orthoferrites can be changed by the synthesis route or substitution of Fe with selected metal cations.

Rajendran et al. ${ }^{1}$ prepared thin films of selected RE-orthoferrites on fused silica using sol-gel processing combined with calcination at $650^{\circ} \mathrm{C}$. Sivakumar et al. ${ }^{2}$ prepared nanocrystalline orthoferrites $\mathrm{GdFeO}_{3}, \mathrm{ErFeO}_{3}$, $\mathrm{TbFeO}_{3}$ and $\mathrm{EuFeO}_{3}$ starting from $\mathrm{Fe}(\mathrm{CO})_{5}$ and corresponding RE-carbonate with the aid of sonochemistry. The orthoferrite precursors were then calcined between 800 and $910{ }^{\circ} \mathrm{C}$ for $24 \mathrm{~h}$ in air atmosphere. Rajendran and Bhattacharya ${ }^{3}$ reported the formation of nanocrystalline orthoferrite powders of selected RE cations combining the coprecipitation and calcination of the gel precursor at 650 to $700{ }^{\circ} \mathrm{C}$ in air. The coprecipitation method was also used to prepare $\mathrm{DyFeO}_{3}$. To a solution of $\mathrm{DyCl}_{3}$ and $\mathrm{FeCl}_{2}$ salts $\mathrm{NaOH}$ solution was added, the coprecipitate was washed and dried, then heated in air at 700 to $1000{ }^{\circ} \mathrm{C}$. In this temperature range XRD showed the formation of a $\mathrm{DyFeO}_{3}$ phase. RE-orthoferrites of $\mathrm{La}, \mathrm{Pr}$ and $\mathrm{Nd}$ were synthesized at $400{ }^{\circ} \mathrm{C}$ using a molten $\mathrm{NaOH}$ flux. ${ }^{5}$ Li et al. ${ }^{6}$ prepared $\mathrm{RE}$ orthoferrites (RE $=\mathrm{La}, \mathrm{Pr}-\mathrm{Tb}$ ) in the form of hollow spheres or solid spheres $(\mathrm{RE}=\mathrm{Dy}-\mathrm{Yb}, \mathrm{Y})$ using the calcination of the RE-Fe citrate complex at $\sim 800{ }^{\circ} \mathrm{C}$. All these REorthoferrites were successfully used for catalytical reduction of NO pollutant by $\mathrm{CO}$ at 200 to $500{ }^{\circ} \mathrm{C}$ and their efficiency could be compared with noble metal catalysts. The effect of $\mathrm{Ca}^{2+}$ substitution on the structural and magnetic properties of RE-orthoferrite was investigated. ${ }^{7}$ Also, $(\mathrm{RE})_{0.7} \mathrm{Ca}_{0.3} \mathrm{FeO}_{3}, \mathrm{RE}=\mathrm{La}, \mathrm{Dy}, \mathrm{Y}, \mathrm{Er}$ or Gd were investigated for possible applications as pressure or $\gamma$-ray sensor. ${ }^{8}$ The structural, morphological and transport properties influenced by doping $\mathrm{Ni}$ for $\mathrm{Fe}$ in $\mathrm{PrFeO}_{3}$ ceramic thin films were investigated as well. ${ }^{9}$

Saraswat et al. ${ }^{10}$ prepared the hydroxide coprecipitate $\mathrm{Fe}(\mathrm{OH})_{3} / \mathrm{Pr}(\mathrm{OH})_{3}$ containing $\mathrm{Fe}(\mathrm{III})(w=5 \%)$. The coprecipitate was heated up to $1100{ }^{\circ} \mathrm{C}$. In the present work we extended the investigation of the system $\mathrm{Fe}_{2} \mathrm{O}_{3}$-" $\mathrm{Pr}_{2} \mathrm{O}_{3}$ " by varying the molar fractions of $\mathrm{Fe}_{2} \mathrm{O}_{3}$ and " $\mathrm{Pr}_{2} \mathrm{O}_{3}$ " with the aim to identify the actual crystal phases formed in this mixed oxides system. Praseodymium has a much more complex oxide chemistry than the other rare earths and this is probably one of the reasons why the formation of $\mathrm{PrFeO}_{3}$ has been less investigated.

\footnotetext{
* Author to whom correspondence should be addressed. (E-mail: ristic@irb.hr)
} 
Table 1. XRD analysis of the samples prepared in the system $\mathrm{Fe}_{2} \mathrm{O}_{3}-$ " $\mathrm{Pr}_{2} \mathrm{O}_{3}$ " where " $\mathrm{Pr}_{2} \mathrm{O}_{3}$ " is virtual composition and $\mathrm{X}$ is unknown phase

\begin{tabular}{|c|c|c|}
\hline Sample & $\begin{array}{l}\text { Initial (molar) ratio } \\
\mathrm{Fe}_{2} \mathrm{O}_{3} \text {-" } \mathrm{Pr}_{2} \mathrm{O}_{3} \text { " } \\
\end{array}$ & $\begin{array}{l}\text { Phase composition as found by XRD } \\
\text { (approx. molar fraction in brackets) }\end{array}$ \\
\hline S1 & $99: 1$ & $\alpha-\mathrm{Fe}_{2} \mathrm{O}_{3}+\mathrm{PrFeO}_{3}(0.02)$ \\
\hline S2 & $97: 3$ & $\alpha-\mathrm{Fe}_{2} \mathrm{O}_{3}+\mathrm{PrFeO}_{3}(0.06)$ \\
\hline S3 & $95: 5$ & $\alpha-\mathrm{Fe}_{2} \mathrm{O}_{3}+\mathrm{PrFeO}_{3}(0.1)$ \\
\hline S4 & $90: 10$ & $\alpha-\mathrm{Fe}_{2} \mathrm{O}_{3}+\mathrm{PrFeO}_{3}(0.2)$ \\
\hline S5 & $85: 15$ & $\alpha-\mathrm{Fe}_{2} \mathrm{O}_{3}+\mathrm{PrFeO}_{3}(0.3)$ \\
\hline S6 & $80: 20$ & $\alpha-\mathrm{Fe}_{2} \mathrm{O}_{3}+\mathrm{PrFeO}_{3}(0.4)$ \\
\hline S7 & $70: 30$ & $\mathrm{PrFeO}_{3}+\alpha-\mathrm{Fe}_{2} \mathrm{O}_{3}(0.4)$ \\
\hline S8 & $50: 50$ & $\mathrm{PrFeO}_{3}+\alpha-\mathrm{Fe}_{2} \mathrm{O}_{3}(\sim 0.01)+\mathrm{X}(<0.02)$ \\
\hline S9 & $30: 70$ & $\mathrm{Pr}_{6} \mathrm{O}_{11}(\leq 1 / 2)+\mathrm{PrFeO}_{3}(\leq 1 / 2)+\mathrm{PrO}_{2}(0.05)+\mathrm{X}(<0.02)$ \\
\hline S10 & $10: 90$ & $\mathrm{Pr}_{6} \mathrm{O}_{11}+\mathrm{PrO}_{2}(0.20)+\mathrm{PrFeO}_{3}(0.10)+\mathrm{X}(<0.02)$ \\
\hline S11 & " $\mathrm{Pr}_{2} \mathrm{O}_{3} "$ & $\operatorname{Pr}_{6} \mathrm{O}_{11}^{(\mathrm{a})}+\mathrm{PrO}_{2}^{(\mathrm{b})}+\mathrm{X}(<0.02)$ \\
\hline
\end{tabular}

(a) Identified according JCPDS PDF card No. 6-329

${ }^{(b)}$ Identified according JCPDS PDF card No. 24-1006

\section{EXPERIMENTAL}

Analytical grade chemicals, $\mathrm{Fe}\left(\mathrm{NO}_{3}\right)_{3} \cdot 9 \mathrm{H}_{2} \mathrm{O}, \mathrm{Pr}\left(\mathrm{NO}_{3}\right)_{3}$ - $6 \mathrm{H}_{2} \mathrm{O}$ and $25 \% \mathrm{NH}_{3}(\mathrm{aq})$, were used. Twice-distilled water was prepared in own laboratory. Mixed hydroxides $\mathrm{Fe}(\mathrm{OH})_{3} / \mathrm{Pr}(\mathrm{OH})_{3}$ were quantitatively coprecipitated by adding $\mathrm{NH}_{4} \mathrm{OH}$ solution to an aqueous solution of $\mathrm{Fe}\left(\mathrm{NO}_{3}\right)_{3}+\operatorname{Pr}\left(\mathrm{NO}_{3}\right)_{3}$ salts. The hydroxide coprecipitates were washed by centrifugation without permitting the peptization of the mixed hydroxide coprecipitate. After drying the coprecipitates were heated in air at $200{ }^{\circ} \mathrm{C}$ for $1 \mathrm{~h}, 400{ }^{\circ} \mathrm{C}$ for $1 \mathrm{~h}, 500{ }^{\circ} \mathrm{C}$ for $1 \mathrm{~h}, 600{ }^{\circ} \mathrm{C}$ for $1 \mathrm{~h}$ and $900{ }^{\circ} \mathrm{C}$ for $4 \mathrm{~h}$. When the heating time was over, the crucibles were removed from the oven and cooled in air to room temperature (RT).

XRD patterns were recorded at $\mathrm{RT}$ using the Philips MPD 1880 diffractormeter $(\mathrm{Cu}-\mathrm{K} \alpha$ radiation, graphite monochromator and proportional counter). ${ }^{57} \mathrm{Fe}$ Mössbauer spectra were recorded at $20{ }^{\circ} \mathrm{C}$ in the transmission mode using the spectrometer setup with WissEl (Starnberg, Germany) products. ${ }^{57} \mathrm{Co}$ in $\mathrm{Rh}$ matrix was used as Mössbauer source. The velocity scale and Mössbauer parameters refer to the metallic $\alpha$ $\mathrm{Fe}$ absorber at $20^{\circ} \mathrm{C}$. The raw spectra were fitted using the MossWin program.

FT-IR spectra were recorded at RT with PerkinElmer spectrometer (model 2000). Powders were mixed with spectroscopically pure $\mathrm{KBr}$ and pressed into tablets using a Carver press. The particles were inspected with a JEOL thermal field emission scanning electron microscope (model JSM-7000F). The inspected particles were not coated with an electrically conductive layer.

\section{RESULTS AND DISCUSSION}

The results of XRD phase analysis of samples $\mathrm{S} 1$ to $\mathrm{S} 11$ with different initial molar ratios in the system $\mathrm{Fe}_{2} \mathrm{O}_{3}$ " $\mathrm{Pr}_{2} \mathrm{O}_{3}$ " are given in Table 1 . The oxides of $\alpha-\mathrm{Fe}_{2} \mathrm{O}_{3}$ and $\mathrm{PrFeO}_{3}$ phases were found in the samples prepared in the initial molar ratio $\alpha-\mathrm{Fe}_{2} \mathrm{O}_{3}$ : " $\mathrm{Pr}_{2} \mathrm{O}_{3} "=70: 30$ (samples $\mathrm{S} 1$ to $\mathrm{S} 7$ ). The phase analysis of sample S8 prepared from equal initial molar ratios of $\mathrm{Fe}_{2} \mathrm{O}_{3}$ and " $\mathrm{Pr}_{2} \mathrm{O}_{3}$ " showed the formation of $\mathrm{PrFeO}_{3}$ and a very small fraction of $\alpha-\mathrm{Fe}_{2} \mathrm{O}_{3}(\sim 0.01)$ plus an undetermined phase $\mathrm{X}(<0.02)$. With an increase in the heating temperature up to $1100{ }^{\circ} \mathrm{C}$ the orthoferrite $\mathrm{PrFeO}_{3}$, as a single phase, is formed. With further increase in the starting " $\mathrm{Pr}_{2} \mathrm{O}_{3}$ " fraction there is a corresponding decrease in the $\mathrm{PrFeO}_{3}$ fraction accompanied by the appearance of praseodymium oxide phases, $\mathrm{Pr}_{6} \mathrm{O}_{11}$ and $\mathrm{PrO}_{2}$. The $\mathrm{Pr}_{6} \mathrm{O}_{11}, \mathrm{PrO}_{2}$ and $\mathrm{X}(<0.02)$ phases were obtained when only the $\operatorname{Pr}(\mathrm{OH})_{3}$ precursor was used (sample S11). The fraction X $(<0.02)$ was not identified with certainty due to very small intensities of diffraction lines and possible overlapping of several other praseodymium oxides. Apart from $\mathrm{Pr}_{2} \mathrm{O}_{3}$ with oxidation number $\mathrm{Pr}^{3+}$ and $\mathrm{PrO}_{2}$ with oxidation number $\mathrm{Pr}^{4+}$ there were several other praseodymium oxides with varying average oxidation numbers such as $\operatorname{Pr}_{7} \mathrm{O}_{12}, \operatorname{Pr}_{9} \mathrm{O}_{16}$, $\mathrm{Pr}_{5} \mathrm{O}_{9}, \operatorname{Pr}_{11} \mathrm{O}_{20}$ and $\operatorname{Pr}_{6} \mathrm{O}_{11} \cdot{ }^{11}$ The formation of these oxide phases depends on the maximum heating temperature, annealing and the cooling atmosphere. In this respect the oxide chemistry of praseodymium is specific among other rare earth elements. More about the stoichiometry of praseodymium oxides is reported in selected references. ${ }^{12-15}$ 


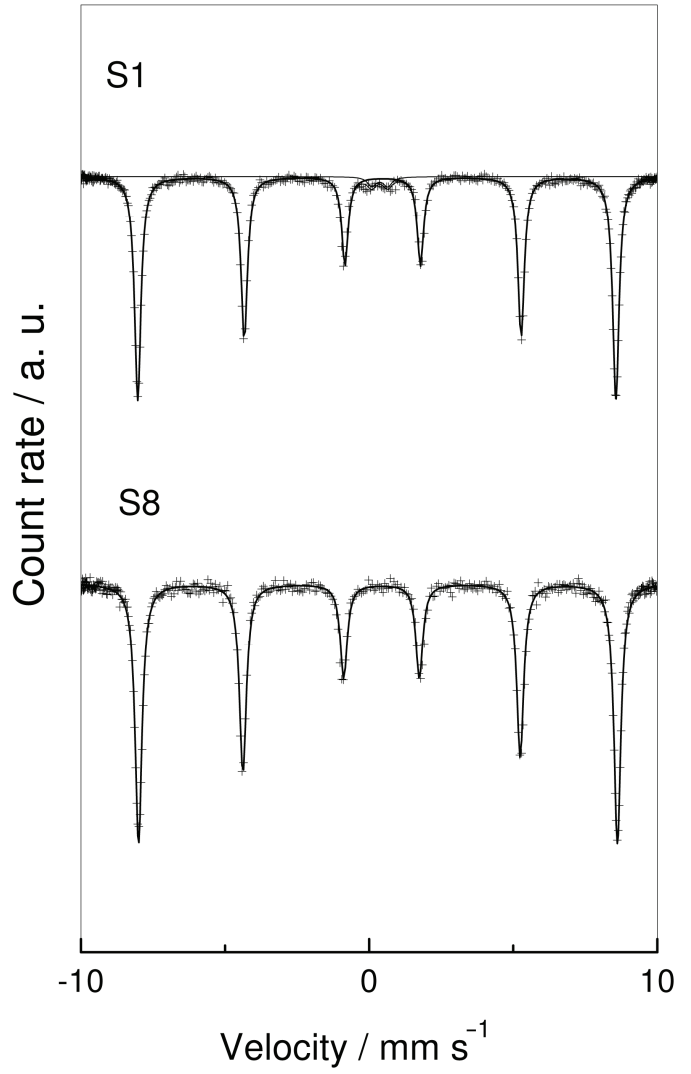

Figure 1. ${ }^{57} \mathrm{Fe}$ Mössbauer spectra of samples S1 and S8, recorded at $20^{\circ} \mathrm{C}$.

Figure 1. shows the Mössbauer spectra of the selected samples (S1 and S8), whereas the calculated Mössbauer parameters for all $\mathrm{Fe}$-containing samples are given in Table 2. RT Mössbauer spectra of $\alpha-\mathrm{Fe}_{2} \mathrm{O}_{3}$ and $\mathrm{PrFeO}_{3}$ showed magnetic hyperfine structure (MHS) with similar Mössbauer parameters. For that reason these two hyperfine magnetically splitted subspectra were fitted as one sextet. The presence of the $\mathrm{PrFeO}_{3}$ phase in dependence on a decrease in the $\alpha-\mathrm{Fe}_{2} \mathrm{O}_{3}$ fraction can be monitored only on the basis of changes in quadrupole splitting, as clearly discernible in Table 2.

The Mössbauer spectrum of sample S1 showed the superposition of one sextet (M) and one central quadrupole doublet $(\mathrm{Q})$ of small relative intensity. The parameters of sextet $\mathrm{M}$ corresponds to to $\alpha-\mathrm{Fe}_{2} \mathrm{O}_{3}$ phase. ${ }^{16}$ Taking into account the results of XRD measurement the central quadrupole doublet $\mathrm{Q}$ can be assigned to very fine $\mathrm{PrFeO}_{3}$ crystallites. The dissolution of $\mathrm{Pr}^{3+}$ cation into $\alpha-\mathrm{Fe}_{2} \mathrm{O}_{3}$ crystal structure is not likely, due to a great difference in the ionic radii of $\mathrm{Fe}^{3+}$ and $\mathrm{Pr}^{3+}$ cations. Samples S2 to S8 show only one sextet which is actually a superposition of two sextets with similar parameters. Eibschütz et al. ${ }^{17}$ measured the Mössbauer spectra of different RE-orthoferrites including $\mathrm{PrFeO}_{3}$. At $296 \mathrm{~K}$, the following parameters for $\mathrm{PrFeO}_{3}$ were measured: $\mathrm{HMF}=51.0 \mathrm{~T}$ and $\mathrm{Eq}=0.012$
Table 2. Calculated Mössbauer parameters at $20^{\circ} \mathrm{C}$, where $\delta$ is isomer shift; $\Delta$ or $\mathrm{Eq}$ is quadrupole splitting; HMF is hyperfine magnetic field. Isomer shift, $\delta$, is given relative to $\alpha-\mathrm{Fe}$ at $20^{\circ} \mathrm{C}$.

\begin{tabular}{ccccccc}
\hline Sample Line & $\begin{array}{c}\delta^{(\mathrm{a})} / \\
\mathrm{mm} \mathrm{s}^{-1}\end{array}$ & $\begin{array}{c}\mathrm{or} \mathrm{Eq}^{(\mathrm{b})} / \\
\mathrm{mm} \mathrm{s}^{-1}\end{array}$ & $\begin{array}{c}\mathrm{HMF}^{(\mathrm{c})} / \\
\mathrm{T}\end{array}$ & $\begin{array}{c}\Gamma / \\
\mathrm{mm} \mathrm{s}^{-1}\end{array}$ & $\begin{array}{c}\text { Area/ } \\
\%\end{array}$ \\
\hline S1 & $\mathrm{M}$ & 0.37 & -0.20 & 51.5 & 0.26 & 97.4 \\
& $\mathrm{Q}$ & 0.37 & 0.55 & - & 0.35 & 2.6 \\
S2 & $\mathrm{M}$ & 0.37 & -0.20 & 51.5 & 0.27 & 100 \\
S3 & $\mathrm{M}$ & 0.37 & -0.19 & 51.5 & 0.27 & 100 \\
S4 & $\mathrm{M}$ & 0.37 & -0.19 & 51.5 & 0.27 & 100 \\
S5 & $\mathrm{M}$ & 0.37 & -0.17 & 51.5 & 0.28 & 100 \\
S6 & $\mathrm{M}$ & 0.37 & -0.17 & 51.5 & 0.28 & 100 \\
S7 & $\mathrm{M}$ & 0.37 & -0.14 & 51.4 & 0.27 & 100 \\
S8 & $\mathrm{M}$ & 0.37 & -0.12 & 51.4 & 0.27 & 100 \\
S9 & $\mathrm{M}$ & 0.37 & -0.04 & 51.2 & 0.27 & 100 \\
S10 & $\mathrm{M}$ & 0.37 & -0.02 & 51.2 & 0.27 & 100 \\
\hline
\end{tabular}

(a) Error $\delta= \pm 0.01 \mathrm{~mm} \mathrm{~s}^{-1}$

(b) Error $\Delta$ or Eq $= \pm 0.01 \mathrm{~mm} \mathrm{~s}^{-1}$

(c) Error $\mathrm{HMF}= \pm 0.2 \mathrm{~T}$

$\mathrm{mm} \mathrm{s}^{-1}$. Saraswat et al. ${ }^{10}$ measured RT Mössbauer parameters for $\mathrm{PrFeO}_{3}: \mathrm{HMF}=50.6 \mathrm{~T}$ and $\mathrm{Eq}=0.06 \mathrm{~mm}$ $\mathrm{s}^{-1}$. A difference in Mössbauer parameters for $\mathrm{PrFeO}_{3}$ can be assigned to different ways of the formation of this orthoferrite. Pasternak et al. ${ }^{18}$ investigated the highpressure (HP) structural, magnetic and electronic properties of RE-orthoferrites with the large $\left(\mathrm{La}^{3+}, \mathrm{Pr}^{3+}\right)$, the intermediate $\left(\mathrm{Eu}^{3+}, \mathrm{Y}^{3+}\right)$ or the smallest $\mathrm{Lu}^{3+}$ cations. $\mathrm{PrFeO}_{3}$ subjected to high pressure shows two eaqully abundant magnetic sublattices due to high-spin and lowspin $\mathrm{Fe}^{3+}$ sites. Starting with $40 \mathrm{GPa}$ the RT Mössbauer spectra show a superposition of two central quadrupole doublets. The quadrupole doublet with smaller $\Delta$ and $\delta$ corresponds to the HS sublattice. By cooling $\mathrm{PrFeO}_{3}$ to $5 \mathrm{~K}$ both high-spin (HS) and low-spin (LS) subspectra become magnetically ordered. ${ }^{18}$

FT-IR spectra of samples S1 to S10 also show gradual changes in dependence on the initial molar ratio $\mathrm{Fe}_{2} \mathrm{O}_{3}$ : " $\mathrm{Pr}_{2} \mathrm{O}_{3}$ ". The spectrum of sample $\mathrm{S} 1$, shown in Figure 2., can be assigned to the hematite phase. Hematite $\left(D_{3 d}{ }^{6}\right.$ symmetry) is characterized by six IR active vibrations, two $A_{2 u}(E \| C)$ and four $E_{u}$ $(\mathrm{E} \perp \mathrm{C}) .{ }^{19,20}$ In the present case, for sample S1 these vibrations were recorded at $630 \mathrm{~cm}^{-1}\left(A_{2 u}\right), 550 \mathrm{~cm}^{-1}$ $\left(E_{u}\right), 475 \mathrm{~cm}^{-1}\left(E_{u}\right), 390 \mathrm{~cm}^{-1}\left(A_{2 u}\right)$ and $344 \mathrm{~cm}^{-1}\left(E_{u}\right)$. Different factors, such as crystallinity, size and morphology of hematite particles determine the positions of the corresponding IR bands. With an increase in " $\mathrm{Pr}_{2} \mathrm{O}_{3}$ " molar fraction the IR band at 630 $\mathrm{cm}^{-1}$, as well as IR band at $390 \mathrm{~cm}^{-1}$ are diminishing. The FT-IR spectrum of sample $\mathrm{S} 8$ with $\mathrm{PrFeO}_{3}$ molar fraction larger than 0.97 , as found with XRD, shows 


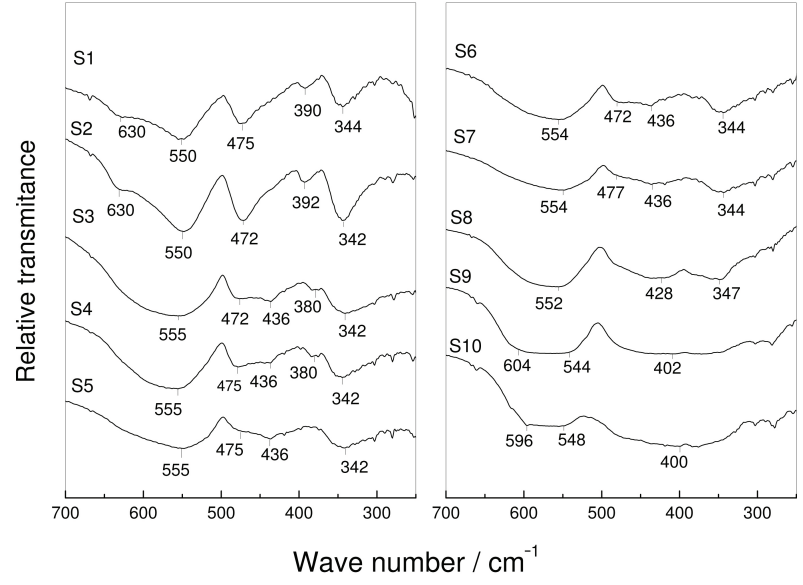

Figure 2. FT-IR spectra of samples S1 to S10, recorded at RT.

three IR bands positioned at 552, 428 and $347 \mathrm{~cm}^{-1}$. Two strong IR bands at $\sim 560 \mathrm{~cm}^{-1}$ and $\sim 440 \mathrm{~cm}^{-1}$ were recorded for $\mathrm{EuFeO}_{3}, \mathrm{GdFeO}_{3}, \mathrm{TbFeO}_{3}$ and $\mathrm{ErFeO}_{3}{ }^{2}$ The IR band at $\sim 560 \mathrm{~cm}^{-1}$ was assigned to the $\mathrm{Fe}-\mathrm{O}$ stretching vibration, whereas the $\sim 440 \mathrm{~cm}^{-1}$ band was interpreted as $\mathrm{O}-\mathrm{Fe}-\mathrm{O}$ deformation vibration. Sivakumara ${ }^{5}$ recorded the IR bands at 562, 421 and $381 \mathrm{~cm}^{-1}$ for $\mathrm{PrFeO}_{3}$, similar to the case of $\mathrm{LaFeO}_{3}{ }^{21}$ The appearance of two IR bands at 421 and $381 \mathrm{~cm}^{-1}$, corresponding to the $\mathrm{O}-\mathrm{Fe}-\mathrm{O}$ deformation vibration, was explained as a deviation from the ideal RE-orthoferrite crystal structure. FT-IR spectrum of sample S10 showed two very broad IR bands positioned at 596-548 and $400 \mathrm{~cm}^{-1}$. In line with XRD analysis it can be concluded that the $\mathrm{Pr}-\mathrm{O}$ and $\mathrm{O}-\mathrm{Pr}-\mathrm{O}$ vibrations of $\mathrm{Pr}_{6} \mathrm{O}_{11}$ and $\mathrm{PrO}_{2}$ predominantly contribute to this FT-IR spectrum.

Figure 3. shows FE-SEM images of selected samples S1 and S8. The image of sample S1 shows micron and submicron hematite particles (Figure 3a.). The image of sample $\mathrm{S} 8$ also shows similar $\mathrm{PrFeO}_{3}$ particles (Figure 3b.). EDS analysis (Figure 4.) of selected area of sample $\mathrm{S} 8$ shows the atomic ratio $\mathrm{Pr}: \mathrm{Fe}$ close to the ratio in $\mathrm{PrFeO}_{3}$ in line with the nominal chemical composition shown in Table 1.

\section{CONCLUSION}

Formation of oxide phases in the system $\mathrm{Pr}-\mathrm{Fe}-\mathrm{O}$ at $900{ }^{\circ} \mathrm{C}$ was monitored. The molar fraction of $\mathrm{PrFeO}_{3}$ increased with increase of the starting molar fraction " $\mathrm{Pr}_{2} \mathrm{O}_{3}$ ". $\mathrm{PrFeO}_{3}$ and small amounts of $\alpha-\mathrm{Fe}_{2} \mathrm{O}_{3}$ and unidentified oxide phase(s) were formed when equal molar fractions of $\mathrm{Fe}_{2} \mathrm{O}_{3}$ and " $\mathrm{Pr}_{2} \mathrm{O}_{3}$ " were used. With futher increase in the molar fraction of " $\operatorname{Pr}_{2} \mathrm{O}_{3}$ ", $\operatorname{Pr}_{6} \mathrm{O}_{11}$ and $\mathrm{PrO}_{2}$ started to become dominant in the phase composition. The small fraction $(<0.02)$ of the same unidentified phase was also obtained upon the calcination of pure $\operatorname{Pr}(\mathrm{OH})_{3}$ precipitate up to $900{ }^{\circ} \mathrm{C}$. It was suggested that this unidentified oxide phase is very proba-
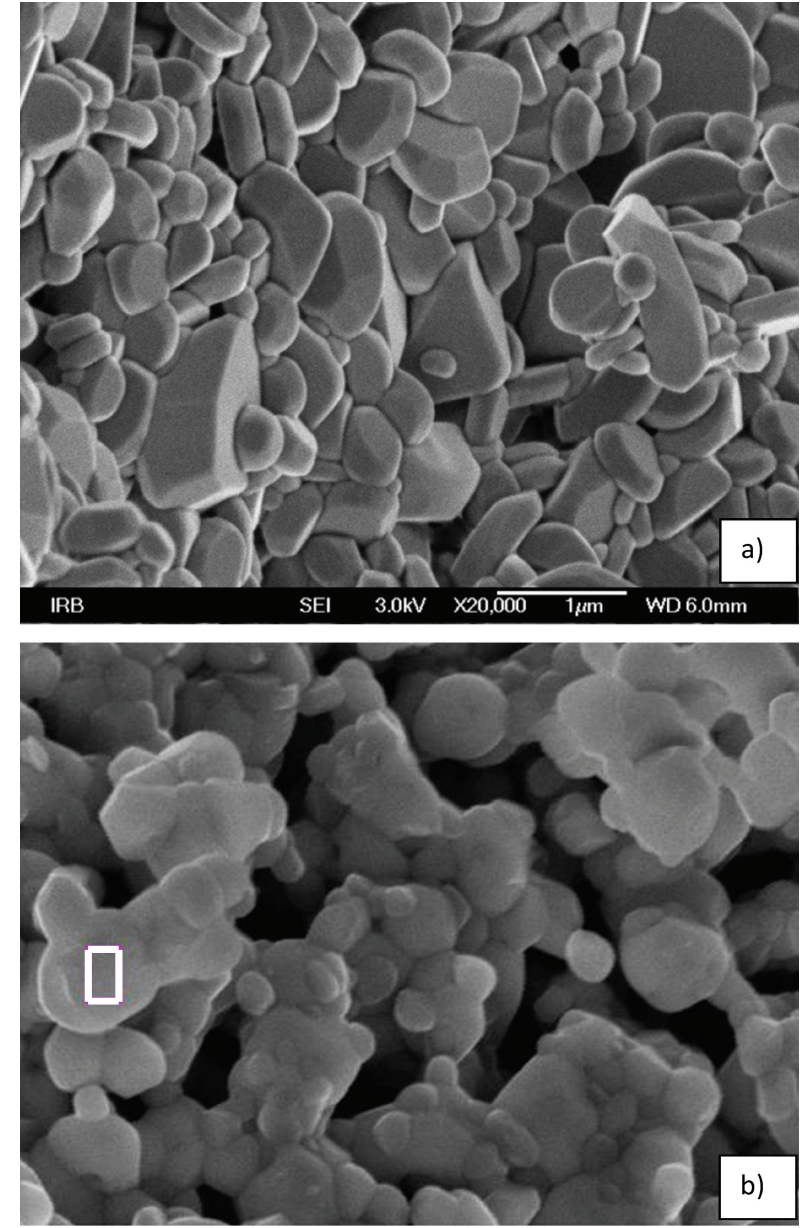

Figure 3. FE-SEM images of samples S1 (a) and S8 (b).

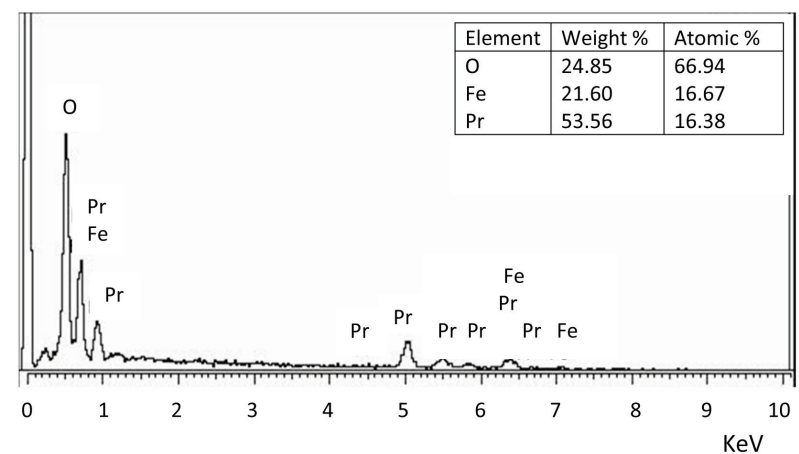

Figure 4. EDS spectrum of the particle in sample S8 (selected area in Figure 3b.).

bly a mixture of other praseodymium oxides with different average oxidation numbers of Pr.

\section{REFERENCES}

1. M. Rajendran, M. Ghanashyam Krishna, and A. K. Bhattacharya, Thin Solids Films 385 (2001) 230-233.

2. M. Sivakumar, A. Gedanken, D. Bhattacharaya, I. Brukental, Y. Yeshurun, W. Zhong, Y. W. Du, I. Felner, and I. Nowik, Chem Mater. 16 (2004) 3623-3632. 
3. M. Rajendran and A. K. Bhattacharya, J. Eur. Ceram. Soc. 26 (2006) 3675-3679.

4. L. Zhu, N. Sakai, T. Yanoh, S. Yano, N. Wada, H. Takeuchi, A. Kurokawa, and Y. Ichiyanagi, Proceedings of Asia Pacific Interdisciplinary Research Conference 2011. J. Physics. Conference Series 352 (2012) 012021.

5. C. Shivakumara, Solid State Commun. 139 (2006) 165-169.

6. X. Li, C. Tang, M. Ai, L. Dong, and Z. Xu, Chem. Mater. 22 (2010) 4879-4889.

7. M. A. Ahmed, S. I. El-Dek, Mater. Sci. Eng. B 128 (2006) 30-33.

8. M. A. Ahmed, S. I. El-Dek, Mater. Lett. 60 (2006) 1437-1446.

9. F. A. Mir, M. Ikram, and R. Kumar, Philosoph. Magazine 92 (2012) 1058-1070

10. I. P. Saraswat, A. C. Vajepi, V. K. Garg, and Nam Prakash, J. Mater. Sci. 16 (1981) 433-438.

11. S. Ferro, Int. J. Electrochem. 2011 (2011) Article ID 561204.

12. F. J. Lincoln, J. R. Sellar, and B. G. Hyde, J. Solid State Chem. 74 (1988) 268-276.

13. Z. C. Kang, L. Eyring, J. Solid State Chem. 75 (1988) 52-59.
14. R. Sharma, H. Hinode, and L. Eyring, J. Solid. State Chem. 92 (1991) 401-419.

15. L. Eyring, J. Alloys Comp. 207/208 (1994) 1-19.

16. E. Murad, J. H. Johnston, Iron Oxides and Oxyhydroxides, in G. J. Long (Ed.) Mössbauer Spectroscopy Applied to Inorganic Chemistry, Vol. 2, Plenum Publ. Corp., NY, 1987, pp. 507-582.

17. M. Eibschütz, S. Shtrikman, and D. Treves, Phys. Rev. 156 (1967) 562-577.

18. M. P. Pasternak, W. M. Xu, G. Kh. Rozenberg, and R. D. Taylor, Electronic, Magnetic and Structural Properties of the $\mathrm{RFeO}_{3}$ Antiferromagnetic-Pervoskites at Very High Pressures, Report LA-UR-02-2720, Edited by Los Alamos National Laboratory, University of California, USA

19. O. Onari, T. Arai, and K. Kudo, Phys. Rev. B 16 (1977) $1717-$ 1721.

20. J. L. Rendon, J. Cornejo, P. De Arambarri, and C. J. Serna, J. Coll. Interface Sci. 92 (1983) 508-516.

21. W. Zheng, R. Liu, D. Peng, and G. Meng, Mater. Lett. 43 (2000) 19-22. 